\title{
COSMOVISIÓN Y RELIGIOSIDAD ANDINA: UNA DINÁMICA HISTORICA DE ENCUENTROS, DESENCUENTROS $Y$ REENCUENTROS
}

\author{
AVELAR ARAUJO SANTOS JUNIOR ${ }^{1}$ \\ $N E P A B / U E S C$
}

\begin{abstract}
RESUMEN: La religiosidad de los pueblos indígenas andinos contemporáneos es constituida por una compleja interacción teológica entre los elementos originales y los cristianizados desde fenómenos e ideologías históricamente producidas, tales como imposición, interpenetración, extirpación, sincretismo, resistencia y reinvención. En este contexto imbricado se desarrolló como forma de realce identitario una cosmovisión particular bastante representativa de sus sentimientos y mentalidades a respecto del mundo, principalmente, en lo que dice respecto al su territorio e sus vivencias comunitarias pautadas en la reciprocidad y en la socialización de las tradiciones. Así, nuestra propuesta en eso articulo es analizar algunos de los diferentes elementos de las representaciones simbólicas, mitológicas y ritualisticas de estas comunidades, caracterizadas por la contraposición entre un persistente dominio del hegemónico y la creativa autonomía creativa.
\end{abstract}

PALABRAS-LLAVES: religiosidad; sincretismo; simbolismo; reinterpretación.

ABSTRACT: Religiosity of contemporary Andean indigenous peoples is constituted by a complex interaction between theology and the original items from the Christianized and ideologies historically produced phenomena such as taxation, interpenetration, removal, syncretism, resistance and reinvention. Embedded in this context was developed as a way of enhancing identity particular worldview is quite representative of their feelings and attitudes about the world, mainly in what it says respect to their territory and their community experiences and patterns of reciprocity in the socialization of traditions. Thus, our proposal in this article is to analyze some of the different elements of the symbolic representation, mythological and ritualistic of these communities, characterized by persistent conflict between a hegemonic dominance of the creative and creative autonomy.

KEYWORDS: religiosity; syncretism; symbolism; reinterpretation.

\footnotetext{
${ }^{1}$ Graduação em Geografia Licenciatura pela Universidade Federal de Sergipe (2001), mestrado em Geografia pela Universidade Federal de Sergipe (2005) - com área de concentração em Arqueologia, e mestrado em "Estudios Ameríndios" pela Universidad Complutense de Madrid (2007). Tem experiência na área de Geografia e Arqueologia, atuando principalmente nos seguintes temas: culturas tradicionais (sobretudo, indígenas), território, identidade, patrimônio, memória, educação e meio ambiente. Vínculo: Núcleo de Estudos e Pesquisas Arqueológicas da Bahia (NEPAB/UESC). E-mail: avelargeo@hotmail.com .
}

Espaço Ameríndio, Porto Alegre, v. 3, n. 1, p. 84-99, jan./jun. 2009. 
AVELAR ARAUJO SANTOS JUNIOR - Cosmovisión y religiosidad andina ...

\section{Creación de una cosmovisión: el preincaico y la sucesión del Imperio Inca}

El proceso histórico de la zona andina en su diversidad paisajística y cultural siguió una trayectoria que evidencia relaciones interculturales en el pensamiento religioso desarrollado, tanto en el tiempo como en el espacio, donde se destacó una tradición básica compartida (RUIZ, 2005, p. 54). Al largo del proceso prehispánico, un orden religioso general se reproducía paralelamente a las particularidades de los diversos pueblos a través de relaciones ideológicas entre instituciones económicas, políticas y culturales. Así, los incas receptores de los ideales y simbologías de las culturas preincaicas añadieran nuevas ideas y dinamicidades a la tradición pan andina.

La concepción animista común de este sistema ideológico tiene como germen la tradición recolectora y cazadora, basada en creencias en espíritus y fuerzas transcendentes que regulaban los cambios astronómicos, naturales y sociales, sobre todo los de subsistencia de su sistema nómada. Durante el proceso de fijación de las poblaciones en territorios comunitarios, la naturaleza y sus respectivas valoraciones simbólicas fueran asumiendo nuevas interpretaciones e importancias.

Os símbolos sagrados funcionam para sintetizar o ethos de um povo - o tom, o caráter e a qualidade da sua vida, seu estilo e disposições morais e estéticos - e sua visão de mundo - o quadro que fazem do que são as coisas na sua simples atualidade, suas idéias mais abrangentes sobre ordem (GEERTZ, 1978, p. 106).

La neolitización y adaptación de un sistema agrícola fueran incrementadas por nuevos conocimientos a cerca de los ciclos de los astros y de la naturaleza, criando nuevas ritualidades asociadas a caza y su carácter mágico, a la fertilidad agrícola y a los sistemas colectivos comunales. Fue establecido como punto básico de este sistema el culto a los antepasados, justificando ideológicamente el asentamiento permanente de la población en territorios delimitados y el necesario control de sus recursos naturales. 
AVELAR ARAUJO SANTOS JUNIOR - Cosmovisión y religiosidad andina ...

Los cambios sucesivos en las concepciones ideológicas y en las representaciones iconográficas acrecentaran nuevas referencias centrales: un ave rapaz (el cóndor o un águila), el jaguar y la serpiente. Otro cambio de suma importancia se observa en la construcción de los centros de integración sociopolítica, económica y religiosa, considerados como espacios de centralización ideológica y ritualística, denotando estrategias de control y dominación social, usando como discurso de convencimiento el propio éxito del sistema agrícola y el sintomático desarrollo socio-económico, como así expresa Chavín de Huántar en su magnitud urbanística.

Chavín es un crisol donde confluyen pensamientos antiguos de los diversos territorios andinos que fueran el germen de una religión universalizada que se extendió desde el Titicaca hasta Colombia, y que convivió con otros cultos regionales y locales (RUIZ, 2005, p.56).

Considerando las variaciones regionales, la religión andina estuve basada en el núcleo común de los conceptos de deidades relativas tanto a la tierra, como a la lluvia y al sol, y a los diferentes productos agrícolas sobre los cuales cada grupo humano fundamentó su economía. Los dioses y las fuerzas naturales eran personificados en seres especiales, como los animales con fuerte esencia de divinidad, y en los propios humanos, sobre todo en el cuerpo de gobernantes y chamanes que tenían el manejo del sobrenatural, habilidad de transitar y de actuar en dos planos de la realidad, el control de las fuerzas de la naturaleza, la curación de enfermedades, capacidades de premoniciones y, por fin, la manipulación política de la sociedad.

El éxito de este sistema político también estuve asociado a la adecuación de la antigua práctica de veneración de los ancestros en cultos con grande participación popular, sobre todo, en ceremonias de enterramiento y en conmemoraciones dedicadas a miembros específicos de generaciones ascendentes dentro de grupos de parentesco. Los soberanos, nobles y patriarcas de los ayllus, tras celebraciones de momificación, asumían un papel de huaca, es decir, de ídolo sagrado y pasaban a ser adorados en fiestas religiosas por diversas generaciones. 
AVELAR ARAUJO SANTOS JUNIOR - Cosmovisión y religiosidad andina ...

Con la organización política instituida desde estructuras imperiales, culminada en los siglos 15 y 16, la formalización religiosa disemina la idea flexible de que los dioses poseían sus aspectos sobrenaturales añadidos a características humanas y que no eran meramente abstractos. La sistemática cíclica, aplicada también en los principios astronómicos, naturales y sociales, aproximaba los dioses a los seres humando y, así, fue incorporada como discurso de distinción por parte de la elite imperial, pues esta se consideraba la legítima detenedora de los medios de manejo entre el divino y el humano. Sin embargo, seguía el paralelismo de estas prácticas estatales con las manifestaciones chamanísticas del culto a los antepasados.

Desde entonces, desemboca como culto de Estado la identificación del Inca con el dios del Sol, Inti, dios del cielo con múltiples facetas que recibía infinidad de atributos mitológicos. La ceremonia oficial del Inti Raimi simbolizaba la conmemoración de los solsticios y el control de las cosechas.

Sendo a mitologia a responsável pelo modelo de reprodução de uma sociedade, contendo ela todo o exemplo de como se deve viver, agir, e morrer, e mais, contendo ainda as respostas de como as coisas passaram a existir, ela não deve ser esquecida nunca (GIORGIS, 1997, p. 16).

Manipulando estos conceptos los gobernantes se erigieron, a través de su mito de origen, en hijos del Sol, adquiriendo así una esencia particular en contraste con los demás de su sociedad, creando una estructura de divinidades paralela a la estructura del Estado. El conjunto divino estaba asociado a los distintos elementos del paisaje: el mar, los peces, las fuentes, las montañas, el cielo, el trueno, el terremoto, los ríos y lagos, animales, etc. Organizados en calendarios astrológicos, en este conjunto de deidades se destacaban el Sol, la Luna, Venus, las Pléyades y Órion.

Esta cosmología era referencia directa a las percepciones geográficas religiosas, donde las deidades denominadas huacas (así como los antepasados protectores) actuaban en tres planos verticales ${ }^{2} \mathrm{y}$

\footnotetext{
${ }^{2}$ En el tópico siguiente trataremos de manera más específica tales dimensiones espaciales y sus respectivas atribuciones religiosas.
} 
AVELAR ARAUJO SANTOS JUNIOR - Cosmovisión y religiosidad andina ...

e se relacionaban en armonía con las cuatro direcciones del plano horizontal.

Los fenómenos de la religiosidad se manifiestan por medio de un sistema de símbolos y normas comportamentales que atribuyen a un determinado espacio, a la primera vista común, una multiplicidad de signos que lo tornan especial a través de un complejo ritualistico, históricamente construido, donde lo real y lo imaginario se conectan en una manera trascendente de aprehender y sentir el mundo. De este modo, el espacio producido por las comunidades andinas adquirían múltiplas dimensiones significativas $\mathrm{y}$, en lo que concierne a la religiosidad, se percebe una contundente relación simbólica entre identidad y territorio, entendido como local de hierofanía (TUAN, 1980, p. 168), es decir, espacio con expresiva centralidad sagrada, categoría fundamental para lo fortalecimiento de las experiencias religiosas colectivas o individuales. Es como suporte estructural de las manifestaciones religiosas que el espacio sagrado cumple su función de intermediario entre el creyente e lo trascendental, o divino.

O lugar sagrado é o lugar simbólico, lugar que unifica os grupos humanos quanto aos valores religiosos, no sentido etimológico de religare, ou, em outras palavras, a junção dos homens no domínio do sagrado e, portanto, vinculados com a divindade além da vida terrena (ROSENDAHL, 2003, p. 207).

La representación iconográfica de las huacas distribuidas ordenadamente en los espacios sagrados eran referencias básicas para los cultos comunitarios en los ayllus y en los grandes actos públicos del centro ceremonial de Cuzco, y sus ofrendas variaban desde sacrificios humanos ${ }^{3}$ o de animales, objetos de oro, plata, textiles, a hojas de coca. Al final, todo este enmarañado de cultos y rituales con importante connotación geopolítica, estaba unido a los fenómenos naturales y se relacionaban con la producción agrícola y con el éxito de las políticas imperiales.

Con la conquista colonial española este variado universo religioso y la estructura política basada en ese sistema empezó a sufrir los

\footnotetext{
${ }^{3}$ En general, los sacrificios humanos (niños, jóvenes y cautivos de guerras) eran realizados en momentos extremos o de transición, como catástrofes naturales o ceremonias de entronización del Inca.
} 
AVELAR ARAUJO SANTOS JUNIOR - Cosmovisión y religiosidad andina ...

primeros síntomas del contacto y su carga funesta. Los cultos de Estado fueran rebatidos con toda vehemencia por los castellanos, pues esos sabían que el sustentáculo de la organización social de los incas se centraba ahí. Sin embargo, en los ayllus rurales, las manifestaciones religiosas indígenas pasó a desarrollar estrategias de mantenimiento de sus prácticas tradicionales que refutasen lo nuevo esquema dominante católico, siendo posible observar rasgos de estas simbologías originarias en las prácticas cotidianas de los grupos indígenas en el área andina contemporánea.

\section{La dinámica de la reinterpretación}

Siendo la pluri-religiosidad una de las temáticas más debatidas en los estudios culturales sobre los pueblos indígenas andinos, notase una cierta centralidad analítica en el carácter sincretista del pensamiento teológico y de la praxis ritual de estas poblaciones. Este sincretismo que, a menudo es subestimado como un signo de impureza por algunas camadas de la sociedad, es antes de todo un hecho histórico y un fenómeno orgánico de síntesis, asociado a un proceso de compleja interpenetración, imposición, reinvención y resistencia.

O simbólico, enquanto forma de conhecimento, apresenta-se como uma linguagem da sociedade sobre si, sobre os "outros" e sobre o mundo. Determina a compreensão da realidade, ao mesmo tempo em que esta modifica e reformula o significado daquele num movimento dialético constante. O conhecimento simbólico assimila as novas experiências sociais, mas, simultaneamente, a sociedade se apropria dele para legitimar, explicar e dar sentido às novas experiências de construção da realidade social (ALTMANN, 1997, p. 167).

Resulta evidente la imposibilidad e inadecuación interpretativa de los complexos de la religiosidad andina tomando como punto de partida únicamente concepciones teológicas y filosóficas occidentales y cuando no se considera las particularidades semánticas y hermenéuticas del propio pensamiento indígena. La yuxtaposición y/o encarnación de lo 
AVELAR ARAUJO SANTOS JUNIOR - Cosmovisión y religiosidad andina ...

cristiano en este marco cultural y conceptual no se dan sin fricciones, incoherencias y inconsistencias. En nuestra perspectiva, asumimos la incapacidad interpretativa y el carácter especulativo de este articulo ${ }^{4}$ por ser meramente una revisión bibliográfica y no un estudio profundo basado en investigaciones y observaciones de campo. Además, la información acumulada por los cronistas españoles de alguna condiciona nuestra valoración sobre este proceso histórico. Pero nos sentimos instigados en comprender los contextos teológicos del encuentro entre esas dos distintas percepciones del mundo y su riqueza cultural.

El politeísmo, el monoteísmo, el animismo, el panteísmo que se han aplicado a las vivencias indígenas son creaciones de las teologías cristianas. Reflejan, no pocas veces, la incapacidad de llamar por sus propios nombres y de aceptar los diferentes sistemas de valores, de análisis de otros pueblos, por lo tanto, las ansias de uniformar las cosas, o el empecinamiento en querer pesar el desarrollo y las organizaciones socio-culturales de los pueblos indígenas a conceptos uniformes occidentales. Por medio de variados mecanismos, al largo de la historia, el clero católico insistió en suprimir las creencias de los nativos en sus huacas y sus mallqui o antespasados.

La religiosidad andina es un "mestizaje religioso", donde diversos elementos andinos son cristianizados y otros tantos aspectos cristianos son andinizados, dinamizando así estrategias de mantenimiento de sus prácticas fundamentales en el cotidiano, mismo el los casos de que algunas de las manifestaciones religiosas indígenas sirvieron apenas de referencia implícita para adaptaciones superficiales y prácticas más toleradas que plenamente fueran asumidas e autónomas. De hecho, sus fiestas, ritos y celebraciones son primicia de su utopía social de la armonía y reciprocidad. Esta polifonía andina no es introspectiva, está abierta y contribuye a la humanización de los no-andinos.

La inteligibilidad religiosa de la vida y del mundo corresponde con ciertas necesidades sentidas y problemas existenciales, matizados en paradigmas semánticos, simbologías, valores, concepciones y relaciones, en suma, en la cosmovisión, que es determinada por un

\footnotetext{
${ }^{4}$ Establecemos aquí una tentativa de análisis exclusivamente sobre los quechuas runas, sin subestimar la gama de la diversidad étnica de la zona andina.
} 
AVELAR ARAUJO SANTOS JUNIOR - Cosmovisión y religiosidad andina ...

conjunto de factores culturales, socio-económicos y hasta por los fenómenos naturales. La apropiación de los conocimientos simbólicos sirve para legitimar, explicar y dar sentido a las nuevas experiencias de construcción de la realidad social, posibilitando renovadas hermenéuticas de los mitos y reestructuraciones de sus respectivos ritos. Los mitos ocupan un lugar entre la historia y la ficción y en ellos se vislumbran algunos eventos acaecidos efectivamente en el pasado y otros hechos en cambio pertenecen exclusivamente a la esfera de lo imaginario (ROSTWOROWSKI, 2000, p. 186). Así, buscar un entendimiento de los mitos permite elucidar aspectos del pensamiento antiguo y comprender la visión diacrónica de su universo.

El sistema simbólico entendido desde las diferentes dimensiones de la practica social - religión, arte, ideología, ciencia, ley, moralidad desempeña un papel fundamental en el desarrollo de la conciencia e vivencia étnica. En el caso de los pueblos andinos, el paradigma occidental-helénico de la religión católica, desde el principio del proceso colonizador, viene se confrontando con aspectos de la cosmovisión y de la religiosidad autóctona. Mismo con las imposiciones de la religión cristiana, sobre todo mediante el poder ideológico, político y militar, los pueblos andinos desarrollaran distintas percepciones y reinterpretaciones (desde sus elementares paradigmas y cosmovisiones) de las lenguajes teológicas cristianas expresas en las concepciones griegas de esencia, naturaleza, persona, sustancia, cuerpo y alma, sobre todo.

Uno de los rasgos más fundamental del pensamiento andino es la relacionalidad de todo, donde el universo es ante de todo un sistema de entes inter-conectados y dependientes uno del otro, regidos por una normatividad exterior (heteronimia) y no existe en sí mismo. Este sistema sigue el principio de la complementariedad, donde cada fenómeno tiene como contraparte un complemento como condición necesaria para ser "completo" y capaz de existir y actuar. La dinámica entre cielo y tierra, sol y luna, varón y mujer, claridad y oscuridad, día y noche, bondad y maldad coexisten para el pensamiento andino de manera inseparable. Así, las manifestaciones de los dioses (seres no absolutos) no san concebidas como fuerzas sui suficientes. La separación occidental entre un ámbito secular y otro religioso (o 
AVELAR ARAUJO SANTOS JUNIOR - Cosmovisión y religiosidad andina ...

numinoso) corresponde con una lógica de exclusión, pero no encaja con el principio holista de la inclusión. Para un runa, hasta la labor agrícola tiene un carácter religioso, donde trabajar la tierra es una forma de oración.

En toda la relación hombre-naturaleza/cosmo-dioses buscan la armonía, un equilibrio cósmico. Su cosmovisión no es un mero acto intelectual, más bien es una cosmosensación, una experiencia y vivencia, un sentir de una sinfonía cósmica (ROSNER, 1997, p. 89).

Cada acto humano (pero también divino) recién llega a su finalidad integral cuando le corresponde un acto recíproco y complementario equivalente de otro(s) sujeto(s). Una acción unilateral distorsiona el equilibrio delicado entre los actores, tanto en lo económico, familiar, organizativo comunal y ético, como también en lo religioso.

El cristianismo llegó a América en alianza con el mercantilismo. Frente a este sistema económico hay en los indígenas otras formas de concebir el trabajo, la producción y la distribución de los recursos. De manera práctica observase la relación de reciprocidad entre el andino agricultor y la naturaleza ${ }^{5}$ o en el sistema de parentesco y compradazo. Los padres crían a sus hijos, pero estos tienen la obligación de restituir este empeño cuidando de sus padres ancianos. Del mismo modo, acreditase que la falta de correspondencia y armonía en el nivel social y religioso puede desencadenar caóticos problemas en la comunidad, en la familia y/o una serie de desastres naturales, como granizo, terremotos, inundaciones, escasez de lluvia, etc.

La ética de los quechuas considera como elementos básicos de ruptura de lo ideal social tales violaciones de la reciprocidad: el robo (suwa), la falta de reciprocidad en el intercambio de bienes $y$ solidariedad; la mentira (llulla), error contra la verdad recíproca y la coherencia del carácter; la ociosidad (qhella), ausencia de reciprocidad en el trabajo, el incumplimiento de cambiamano, del sistema de mingas y de la colaboración voluntaria; y el incesto, la ruptura del intercambio

\footnotetext{
${ }^{5}$ Respetando estrictamente los días intocables, con el "pago" el campesino pide permiso (licenciaykiwan) a la pachamama (madre tierra), para poder abrirla (arar y sembrar); con el ch'allay o la t'inka (esparcir lico chicha) devuelve en forma simbólica algo de sus frutos, suponiendo que 'tiene sed'.
} 
AVELAR ARAUJO SANTOS JUNIOR - Cosmovisión y religiosidad andina ...

de hijos y hijas, representando la distorsión más grave del orden ético y social en el mundo andino.

La relación religiosa de reciprocidad refuta algunas de las concepciones básicas del catolicismo, sobre todo, el concepto de "gracia" como iniciativa unilateral de Dios, sin ninguna contribución recíproca por parte del hombre. El queshwa runa no establece categoría de "gracias" o de "gratuidad", sino de justicia y equilibrio ético.

Las interacciones de mutuabilidad también se manifiestan a nivel cósmico como correspondencia entre micro y macrocosmos. El orden cósmico de los cuerpos celestes, las estaciones, la circulación del agua, los fenómenos climáticos y hasta lo divino tiene su correspondencia y encuentra respuestas correlativas en el ser humano y sus relaciones de subsistencia, sociales y culturales (simbólico-representativos). Las expresiones religiosas andinas, representan mediante actos simbólicos lo que pasa en lo grande, idealizándose de esta manera la continuidad del universo y de la perduración del orden cósmico. Por lo tanto, los "fenómenos de transición" como los cerros, las nubes, el arco-iris, los manantes, los solsticios y los cambios de luna tienen un carácter numinoso y sagrado. La religiosidad en este sentido es la continua tentativa del restablecimiento simbólico y ritual del desequilibrio de la relacionalidad universal, donde los hechos individuales se extiende desde a la comunidad hasta al cosmos en una red de interrelaciones esenciales.

Concatenado a estos principios, la idea de infinidad no es entendida como linear, pero como un movimiento en un espiral interminable, donde tiempo y espacio (pacha ${ }^{6}$ ) se configuran como algo cíclico, sea con respeto a las estaciones del año o con la sucesión de las generaciones. La secuencia escatológica de los ciclos es dialéctica y discontinua, cada ciclo termina con un cataclismo cósmico (pachakuti) que da lugar a otra vuelta, una era nueva en otro nivel.

La concepción andina de "Dios" está muy lejos de la concepción teológica de la filosofía occidental que concibe a Dios como sustancia infinita y que enfatiza los atributos divinos de trascendencia, eternidad, inmutabilidad, omnipotencia y absolutidad. Dios más bien es en cierto

\footnotetext{
${ }^{6}$ El idioma quechua tiene una sola palabra para "tiempo" y "espacio": pacha. Para el universo en su totalidad se usa la expresión teqsimuyu (mundo redondo) y tukuy pacha para el "espacio total".
} 
AVELAR ARAUJO SANTOS JUNIOR - Cosmovisión y religiosidad andina ...

modo parte del cosmo, no como un ente entre otros, sino como el sistema universal de relaciones, o sea, dios es todo en todo. Pero también sufre, siente pena, está triste o con cólera, y los dolores y la injusticia del mundo le afectan, es decir, participa activamente en el quehacer mundano.

La religión incaica tampoco conocía una deidad hacedora y creadora de todo, pues el universo existe desde la eternidad. Los primeros misioneros identificaron a "Dios Creador" del libro de Génesis con el dios incaico Wiraqocha, introduciendo así una concepción ajena al pensamiento andino. Wiraqocha (o Ticsi Wiraqocha Pachayachachi), igual como Pachakamaq, no era creador y hacedor, sino ordenador y movedor de todo el universo, y su primero atributo teológico no es la omnipotencia. El tiene la tarea de "recrear" un cosmos desde el caos (no desde el nada), causado por un pachakuti (cataclismo cósmico), es decir, restablecer un universo ordenado, un sistema seguro y definido de relaciones.

Dios es entonces para el runa de los Andes ante todo la base necesaria para el orden en el universo, tanto natural como social. Así, el pueblo lo llama de Taytacha, como un padre que cuida de sus hijos, manteniendo de esta manera el orden que recién hace posible la vida.

La concepción trinitaria cristiana favorece sustancialmente el acercamiento de los dos paradigmas con respecto a dios, y por lo tanto, el "Dios" cristiano también participa en el rasgo principal del pensamiento andino. Dios trino es en sí mismo relacionalidad. Sin embrago, el pensamiento andino no se concibe en triadas como el pensamiento dialéctico y analógico occidental, pero si en polaridades duales. Para el qheshwa runa sobresalen las dos personas divinas Padre e Hijo, mientras que el Espíritu Santo prácticamente no tiene un lugar propio.

La cristología andina, paralelamente a los preceptos católicos oficiales, considera Jesús Cristo como el hijo de Dios que vino a la tierra para redimir la humanidad con su muerte en la cruz, bajo múltiples manifestaciones sagradas o hierofanías. Sin embargo, lo pensamiento andino manifiesta particulares comprensiones de este hecho. En primer lugar, para los quechuas, Jesús es despojado casi completamente de los aspectos históricos. Los dos hitos cristológicos son el nacimiento 
AVELAR ARAUJO SANTOS JUNIOR - Cosmovisión y religiosidad andina ...

(Navidad) y la muerte en la cruz (Semana Santa), ni la prédica de Jesús, ni su resurrección juegan un papel importante en la religiosidad andina.

Jesús se manifiesta sobre todo en el símbolo de la cruz, que para los runa representa una chakana y sus aspectos transitorios, es decir, un puente entre diferentes regiones cósmicas, entre arriba y abajo, izquierda y derecha. La cruz en la cumbre del cerro establece simbólicamente la relación vital entre micro y macrocosmos, entre cielo y tierra. Así, que para la teología andina la cruz no representa un símbolo de la muerte, sino de la vida que brota a raíz de la relación cósmica, por eso las cruces son verdes (signo de la vida) y sin corpus, y cumple la importante tarea de proteger la comunidad, intermediando la imprescindible relación entre el cielo (lluvia) y la fecundidad de la tierra (ALTMANN, 1997, p. 47).

Para el qheshwa runa, la vida siempre es el producto de una relación complementaria de fuerzas complementarias, lo positivo y lo negativo, lo bueno y lo malo, lo caliente y el frío etc., que siempre están en busca de armonizarse. Un Dios absolutamente transcendente y sui suficiente es estéril e impotente, y no puede ser el "Señor de la Vida". La reinterpretación teológica de la ortodoxia cristiana a través de concepciones andinas pondera con mucha fuerza el elemento femenino de "Dios" en la figura de la "Virgen-pachamama".

Es significativo que la religiosidad andina ha desarrollado una trinidad femenina como contrapeso a la Trinidad cristiana con fuertes rasgos masculinos. La pachamama es Pacha Tierra, Pacha Nusta y Pacha Virgen, siendo esta última la representación de la Virgen María en sus diferentes representaciones (Virgen del Carmen, Candelaria, Natividad, Asunta, de los Remedios, de Belén).

Tanto los Apus como la Pachamama ocupan un lugar estratégico con respecto a la mediación entre diferentes niveles de la realidad (pacha). Esto les da la función de cuidantes y protectores, con relación a los múltiples "fenómenos de transición" (lluvia, rayo, trueno, manantes, arco iris, etc.). De este modo, parte considerable de la religiosidad

\footnotetext{
${ }^{7}$ El campesino considera la pachamama como "virgen", mientras no esté cultivada. Para poder trabajarla - que es un acto de desvirginización - tiene que pedirle permiso (licenciaykiwan) mediante una ofrenda.
} 
AVELAR ARAUJO SANTOS JUNIOR - Cosmovisión y religiosidad andina ...

andina se dedica a rituales protectores y cuidadores con respecto a las variadas deidades ${ }^{8}$ y sus respectivas zonas de actuación.

De manera oportuna, la tradición católica de los Santos ha encontrado en ese conyunto de deidades formas de canalizar y diseminar sus preceptos a los pueblos de la zona andina. Cada Santo es un intermediario con su especialidad propia en la resolución de problemas y dificultades, como la tienen también las deidades andinas.

En Cuzco, por ejemplo, los Santos reemplazaron en la procesión de Corpus Christi a las momias de los Incas. La fiesta de San Juan (a la vez "día del campesino") reemplazó paulatinamente la fiesta incaica de Inti Raymi que tenía como objetivo asegurarse de que los días empezaran nuevamente a crecer. Navidad o la fiesta Niño reemplaza otra fiesta de los incas, el Ohapaq Raymi, la celebración de la gran pascua del sol.

Otro aspecto diferencial entre el pensamiento andino y occidental aplicase a la concepción del tiempo. La palabra quechua Pacha no solo significa "tierra" (pachamama), sino también "espacio" o "nivel" (por ejemplo, kay pacha), y además "tiempo". La concepción quechua no considera categorías de "más-allá" y "de este lado" e las relaciones de continuidad entre los acontecimientos del pasado manifiéstense todavía en el presente, y el futuro, sin tener una forma verbal establecida, ya se anticipa en el presente. Se trata de ubicar los acontecimientos "pasado" en el contexto de la actualidad, redescubrir el sentido de los hechos para una renovada identidad en el autodescubrimiento. Esta percepción cíclica fundamentase en los ciclos agrícolas (barbecho, cosecha, siembra), astronómicos (sol y luna), climatológicos (tiempo de lluvia y de sequía) y de parentescos (sucesión de las generaciones).

La linealidad, continuidad y progresividad del tiempo son conceptos basados en la lógica judío-cristiana, secularizada por las filosofías de la historia del siglo 19, y popularizada en sentido tecnológico y económico en el siglo 20. Desde del punto de vista andino, existen rupturas en el tiempo, momentos decisivos (kairoi) y saltos cualitativos donde al cosmos vuelve a ser caos, los pachakuti (cataclismos).

\footnotetext{
${ }^{8}$ Cada una de estas deidades tiene su complemento sexual: sol y luna, estrella matutina y vespertina, rayo y neblina. Solo el arco iris por su función de "puente" (chakana) encarna en sí mismo la bipolaridad.
} 
AVELAR ARAUJO SANTOS JUNIOR - Cosmovisión y religiosidad andina ...

Mismo sin ser compatibles, los misioneros encontraron en la tripartición andina de diferentes niveles (kay, hanaq y uruay pacha) un modelo apropiado para adecuar a la tripartición cristiana de "cielotierra-infierno".

Para un runa, los tres niveles de pacha pertenecen todos a una misma pacha, unidad espacio-temporal. Hanaqpacha (espacio arriba) se refiere al ámbito de los fenómenos atmosféricos y astronómicos; Kaypacha (este espacio) es el ámbito natural y social de la vida; y Uraypacha (espacio debajo o adentro) se refiere al interior de la pachamama que es tanto al ámbito de la reproducción de la vida y de la muerte. Aunque la gran mayoría de los quechuas acepta hoy las concepciones cristianas de una vida eterna, de un juicio final y del Reino de Dios, ciertamente hay matices muy propios en sus respectivas interpretaciones.

La percepción espacial en sus sentidos sagrados parte desde el principio de la omnipresencia de lo divino. En este panenteísmo, todo el universo es sagrado, porque representa en cada uno de sus partes el orden divino a través de un sistema de relaciones. Sin embargo existen lugares, acontecimientos y tiempos especiales donde las deidades se revelan de manera más densa y perceptiva, asociados a fenómenos de transición.

En el paralelismo entre los sacramentos cristianos y rituales andinos particulares, observase distintos modos de reinterpretación por parte de los quechas sobre todo para el bautismo, el matrimonio y la eucaristía. Por ejemplo, para muchas parejas el matrimonio católico o kasarakuy es solamente el compromiso definitivo después de haber convivido ya mucho tiempo en sirvinakuy, el matrimonio andino, basado en la complementariedad y reciprocidad fecunda cósmica en lo pequeño, con la ayuda de las familias de las parejas y de la comunidad. El varón y la mujer maduran la personalidad sólo en forma de pareja, o sea, en armonía matrimonial.

Otros sacramentos católicos encuentran mucho menos aceptación entre la población andina, debido a su distancia conceptual y ritual del mundo andino. 
AVELAR ARAUJO SANTOS JUNIOR - Cosmovisión y religiosidad andina ...

\section{Consideraciones finales}

La percepción de la religiosidad andina contemporánea presentase desde nuevos paradigmas analíticos, donde el indígena ha cambiado de "objeto" a "sujeto", del oprimido y explotado al protagonista de su propia liberación, siendo ellos mismos los artífices de su futuro. El indigenismo dio paso a la indianidad, y así nuevas propuestas son establecidas, donde los pueblos no aceptan resignarse $y$ integrarse simplemente a la cultura hegemónica, sino presentar y vivir su cultura como alternativa autónoma y más apropiada a sus demandas particulares.

El indígena indoctrinado y rechazado, reducido, cristianizado de manera compulsiva ha asumido la condición de "indio cristiano", pero capaz de desarrollar su propia teología y cosmovisión, invitando así a un diálogo ecuménico entre religiones.

El modelo de la "cristianización de los indígenas" ha cambiado por la propia capacidad de resistencia de estos pueblos, y hoy se toma el camino en dirección contraria hacia "la indigenización de la iglesia y la sociedad" en Ameríndia. Este contexto, reflecte el proyecto de la búsqueda de una sociedad pluricultural y multiétnica, posibilitando nuevas y necesarias posibilidades para una sociedad que todavía sigue manteniendo discurso e ideologías falsas que distancian aún más la convivencia equilibrada entre los grupos indígenas y la sociedad envolvente.

\section{Referencias bibliográficas}

ALTMANN, Lori. Madija: um povo entre a floresta e o rio, trilhas da produção simbólica Kulina. In: SIDEKUN, Antônio (Org). O imaginário religioso indígena. São Leopoldo: Unisinos, 1997. p. 163-171.

CAROLINA, Berna. A intríseca relação entre religião e política nas sociedades précolombianas: poder centra: igreja ou Estado? A m e r í n d i a, São Paulo, v. 2, n. 2, 2006.

COOK, Anita G. Las deidades huari y sus orígenes altiplánicos. In: Los dioses del antiguo Perú (Arte y tesoros del Perú). Lima: BCR, 2000. p. 39-65. 
AVELAR ARAUJO SANTOS JUNIOR - Cosmovisión y religiosidad andina ...

GEERTZ, Clifford. A interpretação das culturas. Rio de Janeiro: Zahar, 1978.

GIORGIS, Paula Caleffi. A história no mito: proposta metodológica. In: SIDEKUN, Antônio (Org). O imaginário religioso indígena. São Leopoldo: Unisinos, 1997. p. 1525 .

MUNZEL, Mark. Las religiones ameríndias: ¿obstáculos a la modernización? Bulletin de la Société Suisse des Americanistes, Genebra, n. 59-60, p. 125-132, 1995-1996.

ROSENDAHL, Zeny. O sagrado e o espaço. In: CASTRO, Iná Elias de; GOMES, Paulo Cesar da Costa; CORRÊA, Roberto Lobato (Orgs). Explorações geográficas: percursos no fim do Século. Rio de Janeiro: Bertrand Brasil, 1997. p. 119-153.

- Espaço, cultura e religião: dimensões de análise. In: CORRÊA, Roberto Lobato; ROSENDAHL, Zeny (Orgs.). Introdução à geografia cultural. Rio de Janeiro: Bertrand Brasil, 2003. p. 187-224.

ROSNER, Enrique. El proceso de formación del imaginário religiosos indigena andino. In: SIDEKUN, Antônio (Org). O imaginário religioso indígena. São Leopoldo: Unisinos, 1997. p. 26-48.

ROSTWOROWSKI, María. La religiosidad andina. In: Los dioses del antiguo Perú (Arte e tesoros del Perú). Lima: BCR, 2000. p. 185-221.

RUIZ, Andrés Ciudad. Cosmovisión y ideología en los andes prehispánicos. In: Perú: Indígena y Virreinal. Espana: Museo Nacional de Arte de Cataluña: Ministerio de Cultura y Biblioteca Nacional, 2005. p. 54-61. Disponível em: http://www.seacex.es/documentos/peru 08 cosmovision.pdf . Acesso em: 30 jun. 2009.

SUESS, Paulo. Reconhecimento e protagonismo: apontamentos em defesa do projeto histórico dos outros. In: SIDEKUN, Antônio (Org.). O imaginário religioso indígena. São Leopoldo: Unisinos, 1997.

TUAN, Yi-fu. Topofilia: um estudo da percepção, atitudes e valores do meio ambiente. São Paulo: Editora Difel, 1980. 